\title{
A Nutritional Evaluation of the Berry of a New Grape: 'Karaerik' (Vitis vinifera L.)
}

\author{
Aynur Kurt ${ }^{\mathrm{a}}$, Nesrin ColaK ${ }^{\mathrm{a}}$, Aydin Sükrü Bengu ${ }^{\mathrm{b}}$, Ali GundoĞdu ${ }^{\mathrm{c}}$, Erdal \\ AkPinar $^{\mathrm{d}}$, Sema Hayirlioglu-Ayaz ${ }^{\mathrm{a}}$, And Faik Ahmet Ayaz ${ }^{*}$ \\ ${ }^{a}$ Department of Biology, Faculty of Science, Karadeniz Technical University, 61080 Trabzon, Turkey \\ ${ }^{\mathrm{b}}$ Department of Medical Services and Techniques, Vocational School of Health Services Medical Laboratory \\ Techniques Program Bingöl University, 12000 Bingöl, Turkey \\ ${ }^{c}$ Department of Food Engineering, Faculty of Engineering \& Natural Sciences, Gümüşhane University, 29100 \\ Gümüşhane, Turkey \\ d Social Sciences Training Department, Faculty of Education, Erzincan Binali Yıldırım University, 24030, \\ Erzincan, Turkey \\ ${ }^{*}$ Corresponding author \\ faa@ktu.edu.tr
}

TEL AND FAX: +90-462-377-37 12

Received: 29 January 2018; Published online: 18 October 2018

\begin{abstract}
Grape berries are a good source of nutrients and nutraceuticals and have many benefits for human health. Growing interest in the export potential and consumption of a new grape (cv. Karaerik), cultivated as a table grape in Turkey, encouraged us to profile its major nutrient contents from six different locations. Due to its popularity, the nutritional value of this grape berry needs to be investigated to ascertain its potential economic and health benefits. The most abundant sugars in the grape berry were fructose and glucose (peel/whole fruit; averages 236.57 and 127.87 , and 183.36 and $108.60 \mathrm{~g} \mathrm{~kg}^{-1}$ fresh weight, respectively), while the major organic acids were tartaric and malic acids (7.17 and 2.81, and 2.61 and $1.76 \mathrm{~g} \mathrm{~kg}^{-1}$ fresh weight, respectively). Linoleic acid (peel/whole fruit/seed; 37.14, 33.12 and $57.83 \%$, respectively) was the predominant fatty acid, while potassium (peel/whole fruit/seed; 9331.5 , 10226.33 and $5354 \mu \mathrm{g} / \mathrm{g}$ dry weight, respectively) was the predominant mineral, followed by phosphorus $(1592.8,2672$ and 3072.67) in the berry. Our results demonstrate that the nutrient components and physicochemical parameters varied significantly among the sampling locations. The grape berry contains considerable quantities of potentially beneficial healthy nutrients worthy of further evaluation.
\end{abstract}

Keywords: Vitis vinifera ; Karaerik, sugar; organic acid; fatty acid; mineral

\section{Introduction}

The consumption of fruits and vegetables is a key component of a healthy diet in humans and for protection against various degenerative diseases, such as cancer, cardiovascular diseases, diabetes, pulmonary disorders, and Alzheimer's (Ferretti, Turco, \& Bacchetti, 2014; Hyson, 2011) by reducing the risk of their development (Slavin
\& Lloyd, 2012). The benefits obtained from foods are associated with their nutrients (vitamins, minerals, organic acids, and mono- and polyunsaturated fatty acids), dietary fibers and polyphenolic antioxidants (Kurt et al., 2017; Liu, 2013). Information regarding the quality and quantity of nutrients or neutraceuticals in fruits or vegetables during the pre- and post-harvest periods is particularly important when assess- 
ing the contribution of the consumption of these foods to protection against the diseases cited above (Kurt et al., 2017).

Grapes (Vitis spp.) are one of the most important and widely cultivated fruit crops around the world. Of the various Vitis species (V. labrusca, $V$. rotundifolia and $V$. vinifera), $V$. vinifera $\mathrm{L}$. is the most prevalent and widely cultivated worldwide (Pavlousek \& Kumsta, 2011). During the 2014-2015 production period, 21.7 million tons of grapes were produced. Turkey is one of the world's three largest producers, at 9 million tons (9.2\%) (Xia, Deng, Guo, \& Li, 2010).

Grapes can be consumed fresh (table grapes) or used in the production of wine, grape juice and raisins (Zhou \& Raffoul, 2012). The beneficial effects of grapes and grape-derivative food products are associated with their nutritional and polyphenolic compositions (Mikulic-Petkovsek, Schmitzer, Slatnar, Stampar, \& Veberic, 2012; Santos et al., 2011) and many studies have been published concerning their nutritional value (Kurt et al., 2017). The organoleptic quality, flavor and stability of grape berries depend to a large extent on the relative and total amounts of sugars and organic acids that maintain grape berry quality and determine its nutritive value. The nature and concentration of these constituents affect the market value because they contribute to grapes' sweetness and acidity, properties that vary among species, cvs. or varieties. For instance, grape seeds are a rich source of linoleic acid and a-linolenic acid, polyunsaturated fatty acids which prevent cardiovascular diseases (Kurt et al., 2017).

The 'Karaerik' grape, so named because of its black color and large-grained berries, is cultivated as a table grape, mainly around Üzümlü and the surrounding areas in Erzincan, Turkey (Figure 1). The taste lies on a fine point between mildly sour and sweet, with a specific aroma not found in other grapes (Akpinar \& Yiğit, 2011; Güner \& Aslan, 2012). It is generally regarded as a table grape. In addition, the syrup of the Karaerik grape is traditionally processed in different forms such as vinegar, molasses and dried pulp by local residents (Akpinar \& Yiğit, 2011). Growing interest has focused on the phenolics and antioxidant capacity of the new grape berry. In this regard, the presence of a feruloyl derivative of anthocyanins (malvidin3 -feruloylglucoside) that has very recently been identified and quantified in the grape constitutes the first evidence for the $V$. vinifera grape (Ayaz et al., 2017).

The grape's increasing export potential and growing consumption as a table grape, together with its unique anthocyanin composition among all V. vinifera grapes (Ayaz et al., 2017), encouraged us to profile the nutritional value of the new grape cultivar, 'Karaerik', in detail. Apart from a very few phenological and ampelographic studies, the present research constitutes the first record of the nutrient composition of the grape berry. The aim of the present study was to characterize and compare various physicochemical parameters and nutritional composition changes (soluble sugars, organic acids, fatty acids, and minerals) in berries of the new grape (Karaerik) that is particularly widely grown in the region.

\section{Materials and Methods}

\subsection{Chemicals and Reagents}

All solvents were of HPLC quality and analytical grade. Natrium hydroxide $(\mathrm{NaOH})$, $\mathrm{KH}_{2} \mathrm{PO}_{4}$, methanol and acetonitrile used for HPLC were purchased from MERCK (Darmstadt, Germany), and deionized water was prepared using a Simplicity 185 deionizer (Millipore, Bedford, MA, USA). Water for LC-MS analysis was of Milli-Q quality.

Analytical grade reference compounds used for sugar [ (>99\%, glucose (CAS 50-99-7), fructose (CAS 57-48-7), sucrose (CAS 57-50-1), maltose (CAS 6363-53-7) and lactose (CAS 64044-51$5)]$ and organic acid [ (>99\%, malic acid (CAS 6915-15-7), ascorbic acid (CAS 50-81-7) and citric acid (CAS 77-92-9)] calibration and quantification were purchased from Sigma-Aldrich Fine Chemicals (St. Louis, MO, USA). The fatty acid methyl esters (FAME) mixture (Supelco 37 FAME mix, $10 \mathrm{mg} / \mathrm{mL}$ FAMEs in methylen chloride 47885-U, Supelco, USA) and HCSM (hexane/chloroform/sodium methoxide Sigma 403067) solution were also GC-MS or LCMS grade $(>99 \%)$.

Calibration and internal standards for ICP-MS 
measurements were supplied by Agilent Technologies (Santa Clara, CA, USA) and Inorganic Ventures (Virginia, United States). These standards are traceable to the National Institute of Standards and Technology (NIST).

\subsection{Plant material}

Black berries of the 'Karaerik' ( $V$. vinifera L.) grape at commercial maturity were sampled from six locations where they are widely grown in the district of Üzümlü and the surrounding area (Figure 1). Bunches of grape berries were randomly handpicked on sunny days from four 15year-old grape plants in vineyards in the late morning at altitudes of 1250 and $1600 \mathrm{~m}$ above sea level (a.s.l.) on the hills of Üzümlü, Bayırbağ, Karakaya, Pişkidağ, Göllerköyü and Çağlayan in Erzincan (eastern Anatolia, Turkey). The distance between trees in each location was greater than $100 \mathrm{~m}$. Grape bunches of moderate size, weighing 2-3 $\mathrm{kg}$ were collected in triplicate from six lots for each of the six sampling locations. These bunches were then combined for each location. From these bulk grape samples $(2-3 \mathrm{~kg})$, approximately 100 berries were separately prepared for analysis.

Sampled grape berries were immediately washed free of any residues (dead flower debris or decayed, abnormal or immature berries not at the correct maturity) using distilled water. They were kept cold below $\pm 4{ }^{\circ} \mathrm{C}$ and transported to the laboratory within approximately $2.5-3 \mathrm{~h}$. The berry samples were treated with liquid nitrogen $\left(-195.79^{\circ} \mathrm{C}\right)$ and stored at $-80^{\circ} \mathrm{C}$ until further analysis. Part of each sample was set aside for physicochemical analysis. After lyophilization, the hard, dried grape berries were crushed with a steel hammer and then ground to a fine powder using a stainless steel mill for further analysis as described below.

\subsection{Determination of physicochemical parameters}

An Association of Official Agricultural Chemists (2003) with slight modification was used to determine $\mathrm{pH}$ values and titratable acidity (TA) contents as recently described elsewhere by Kurt et al. (2017). The TA was analyzed from a prepared $30 \mathrm{ml}$ fresh juice sample by titration with standardized $0.1 \mathrm{~N} \mathrm{NaOH}$ to $\mathrm{pH} 8.2$ according to Kurt et al. (2017) and content was expressed as citric acid equivalents (CAE) $\mathrm{g} \mathrm{kg}^{-1}$ of fw berry. The whole grape berry from each location in triplicate was analyzed in terms of both moisture content (MC) and dry matter content (DM) according to an official Association of Official Agricultural Chemists (2011) with slight changes as recently described elsewhere by Kurt et al. (2017). Total soluble solids (TSS, \%) content was measured in juice pressed from the whole grape berry from each location using a digital refractometer (RE 5 Mettler-Toledo, Tokyo, Japan) at $21{ }^{\circ} \mathrm{C}$. Firmness $\left(\mathrm{g} \mathrm{mm}^{-1}\right)$ was measured with a penetrometer (FT-327) with an 11-mm diameter probe from three different areas (top, middle and bottom) of the whole grape berry. The fruit size (FS) of the whole grape berry (40 berries from six separate stalks) from each location was measured using a digital caliper with a sensitivity of $0.01 \mathrm{~mm}$.

\subsection{Extraction and determination of soluble sugars and organic acids}

The extraction protocol described by Kurt et al. (2017) with slight changes was followed for the separation and quantification of sugars and organic acids in the berry of the 'Karaerik' grape. The fresh weighed peel (avg., $25 \mathrm{~g} \mathrm{fw}$ ) and deseeded whole grape berry (avg., $100 \mathrm{~g} \mathrm{fw}$ ) samples were first treated with liquid nitrogen ($195.79^{\circ} \mathrm{C}$ ) and homogenized at maximum speed in a blender using aqueous ethanol $(80 \%, \mathrm{v} / \mathrm{v}$, $20 \mathrm{ml} \times 3$ ) for approximately $10 \mathrm{~min}$, depending on tissue softness. The homogenates of both grape samples were centrifuged, and the supernatants were then separated. The residues were washed three times $(20 \mathrm{ml} \times 2)$ with the same extraction solvent, and then centrifuged. All supernatants were combined, centrifuged and evaporated under vacuum using a rotary evaporator below $35{ }^{\circ} \mathrm{C}$ (Heidolph, Germany). The slurry was lyophilized, and the dry sample was dissolved in $5 \mathrm{ml}$ deionized water and centrifuged under the same conditions and fractioned by solid-phase ex- 


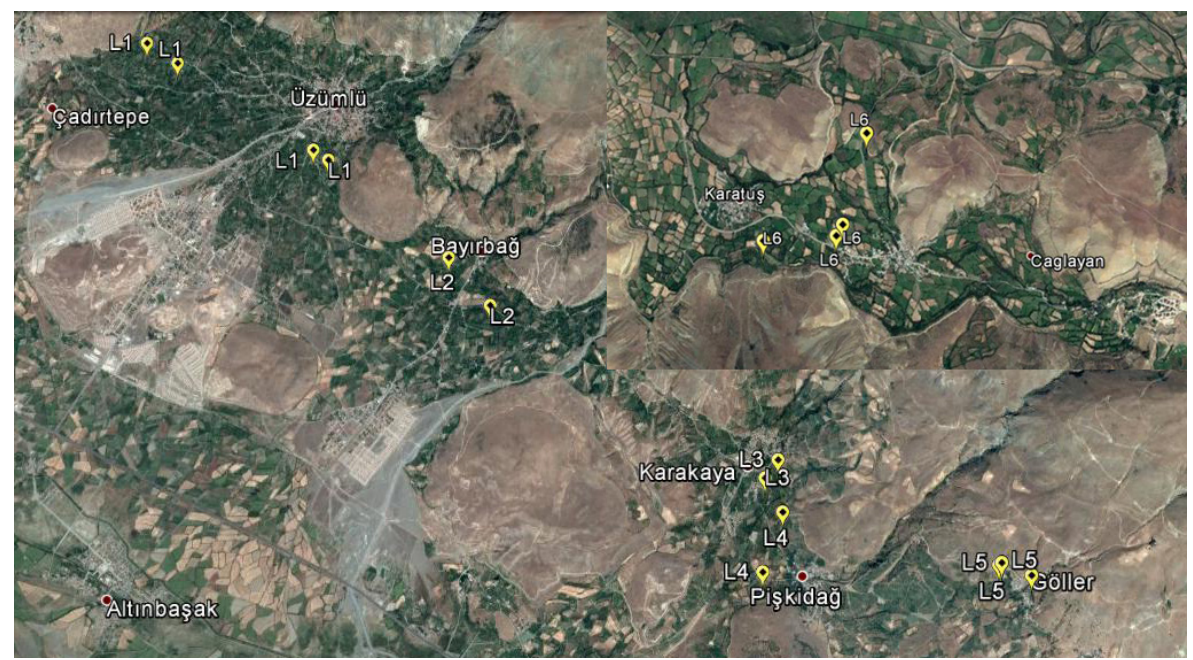

Figure 1: Locations of the 'Karaerik' black grape ( V. vinifera L.) from east Anatolia (Erzincan, Turkey)

L1; Üzümlü $\left(39^{\circ} 42^{\prime} 52.41^{\prime \prime} \mathrm{N}, \quad 39^{\circ} 40^{\prime} 38.17^{\prime \prime} \mathrm{E}, \quad 1361 ; \quad 39^{\circ} 42^{\prime} 45.55^{\prime \prime} \mathrm{N}, \quad 39^{\circ} 40^{\prime} 52.80^{\prime \prime} \mathrm{E}, 1365 ; \quad 39^{\circ} 42^{\prime} 13.09^{\prime \prime} \mathrm{N}\right.$, $\left.39^{\circ} 42^{\prime} 03.06^{\prime \prime} \mathrm{E}, \quad 1367 ; 39^{\circ} 42^{\prime} 16.26^{\prime \prime} \mathrm{N}, 39^{\circ} 41^{\prime} 56.25^{\prime \prime} \mathrm{E}, 1377\right)$, L2; Bayırbă̆ $\left(39^{\circ} 41^{\prime} 41.32^{\prime \prime} \mathrm{N}, 39^{\circ} 42^{\prime} 58.06^{\prime \prime} \mathrm{E}\right.$,

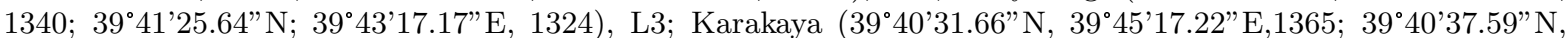

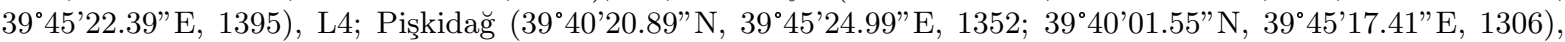

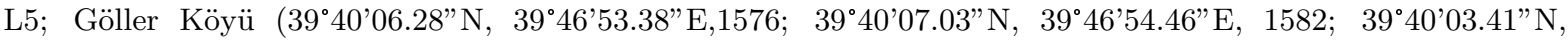
$\left.39^{\circ} 47^{\prime} 06.40^{\prime \prime} \mathrm{E}, 1611\right)$, L6; Çă̆layan-Yamaçlı $\left(39^{\circ} 36^{\prime} 01.97^{\prime \prime} \mathrm{N}, 39^{\circ} 41^{\prime} 36.21^{\prime \prime} \mathrm{E}, 1239 ; 39^{\circ} 45^{\prime} 29.61^{\prime \prime} \mathrm{N}, 39^{\circ} 41^{\prime} 24.96^{\prime \prime} \mathrm{E}\right.$, 1243 ; $39^{\circ} 35^{\prime} 27.46^{\prime \prime} \mathrm{N}, 39^{\circ} 40^{\prime} 55.44^{\prime \prime} \mathrm{E}, 1261$; 39 $35^{\prime} 33.17^{\prime \prime} \mathrm{N}, 39^{\circ} 41^{\prime} 27.44^{\prime \prime} \mathrm{E}, 1240$ )

traction (SPE). Solid-phase extraction columns (Grace Pure C-18, max 500 mg packed bed, 3 $\mathrm{mL}$, Deerfield, IL, USA) were rinsed with $100 \%$ and $80 \%$ methanol $(5 \mathrm{~mL})$, and then activated with deionized water $(2 \times 5 \mathrm{~mL})$. The aqueous combined extract was then passed through the columns. Hydrophobic compounds were absorbed onto the columns, while sugars and other polar compounds were eluted with deionized water (aqueous fraction). The aqueous fraction obtained from the SPE fractionation was used for soluble sugar and organic acid analysis.

An Agilent 1100 equipped with a quarternary HPLC pump, microvacuum degasser (MVD), thermostated column compartment (TCC), refractive index detector (RID), multivariable wavelength detector (MWD) and diode array detector (DAD) (Palo Alto, CA, USA) was used for sugar and organic acid analysis. Sugars were detected using a HP 1100 series RI detector and elutions were performed on a Fortis C18 Nucleosil C18 carbohydrate analytical column (250 x $4.6 \mathrm{~mm}$ i.d., $5 \mu$ particle size, Fortis Technolo- gies Ltd., Neston, Cheshire, UK) with a column temperature of $25^{\circ} \mathrm{C}$. The mobile phase used was acetonitrile:water $(79: 21, \mathrm{v} / \mathrm{v})$ for isocratic

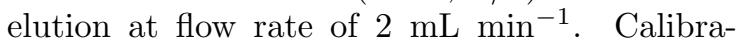
tion curves for the standard solutions at ranged between $10-0.5 \mathrm{mg} \mathrm{mL}^{-1}$ and were based on a five-point calibration calculated for each sugar (glucose, fructose and sucrose). These were later used for assessing the concentrations corresponding to the different peaks in the chromatograms. Quantification was performed by comparing the peak areas with those of the respective external standards using HP ChemStation (HewlettPackard, Palo Alto, CA, USA) software. Linearity, and limit of detection (LOD) calculated from three times the noise level of the response, limit of quantification (LOQ) calculated from 10 times the noise level of the response, and the average recovery (\%RSD) of this method under the present chromatographic conditions were as follows:

- glucose, $\mathrm{R}^{2}=0.9999, \mathrm{y}=37802.74678 \mathrm{x}-$ 6536.136, LOD; 0.699, LOQ; 2.330, \%RSD; 
0.024

- fructose, $\mathrm{R}^{2}=0.9997, \mathrm{y}=78177.37605 \mathrm{x}+$ 9892.674, LOD; 0.237, LOQ; 0.791, \%RSD; 0.016

- and sucrose, $\mathrm{R}^{2}=0.9999, \mathrm{y}=80451.7799 \mathrm{x}$ + 1092.3479, LOD; 0.139, LOQ; 0.460, \%RSD; 0.009

Based on sugar concentration data, the sweetness index (SI) and total sweetness index (TSI) were calculated using the formulae $\mathrm{SI}=(1.00$ $[$ glucose $])+(2.30$ [ fructose $])+(1.35$ [ sucrose $])$ and TSI $=(1.00 \times[$ sucrose $])+(0.76 \times[$ glucose $])$ $+(1.50 \mathrm{x}$ [ fructose] $)$, as previously described by Magwaza and Opara (2015).

Organic acids were detected using the same HPLC system. Elution of the organic acid standard solutions and samples was performed on a Fortis C18 (250 x 4.6 mm i.d., $5 \mu$ particle size, Fortis Technologies Ltd., Neston, Cheshire, UK) column. The mobile phase was a $0.02 \mathrm{M}$ potassium phosphate solution $\left(\mathrm{KH}_{2} \mathrm{PO}_{4}, \mathrm{pH} 3.01\right)$ at

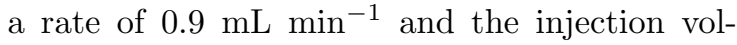
ume was $10 \mu \mathrm{L}$. Temperature of the column was held constant at $25^{\circ} \mathrm{C}$. The automatic injection system used was a $10 \mathrm{~mL}$ sample loop and organic acids were detected using a HP 1100 series DAD set at $214 \mathrm{~nm}$. Standard solutions and extracts were filtered through a prefilter and finally a $0.22 \mu \mathrm{m}$ milipore membrane before they were injected onto the column. To prevent the loss of ascorbic acid, standard solutions and extracted samples were protected from light using amber flasks. Quantification was performed by comparing the peak areas with those of the respective external standards using $\mathrm{HP}$ ChemStation (Hewlett-Packard, Palo Alto, CA, USA) software. The calibration curves were plotted by the peak area versus concentration of each organic acid based on a five-point calibration in a concentration range of $0.05-0.5 \mathrm{mg} \mathrm{mL}^{-1}$. Linearity, and limit of detection (LOD) calculated from three times the noise level of the response, limit of quantification (LOQ) calculated from 10 times the noise level of the response, and the average recovery (\%RSD) of this method under the present chromatographic conditions were as follows:
- malic acid, $\mathrm{R}^{2}=0.9998, \mathrm{y}=897.44394 \mathrm{x}+$ 2.65149, LOD; 0.010, LOQ; 0.034, \%RSD; 1.347

- tartaric acid, $\mathrm{R}^{2}=0.9998, \mathrm{y}=1772.18677 \mathrm{x}$ +5.49515 , LOD; 0.008, LOQ; 0.029, \%RSD; 1.181

- citric acid, $\mathrm{R}^{2}=0.9999, \quad \mathrm{y}=616.1977 \mathrm{x}$ +0.37935, LOD; 0.015, LOQ; 0.517, \%RSD; 2.026

- and ascorbic acid; $\mathrm{R}^{2}=0.9999, \quad \mathrm{y}=$ 7453.28005x + 23.56019, LOD; 0.021, LOQ; $0.071, \% \mathrm{RSD} ; 2.616$

Based on the above validation statistics, both methods of analysis possess good sensitivity, precision, and repeatability. Linearity was confirmed over a wide calibration range with regression coefficients higher than 0.999, suitable for detecting sugars and organic acids. These two methods can therefore be recommended for routine compositional analyses.

\subsection{Lipid extraction and analysis of fatty acid methyl esters (FAME)}

The conventional method of total lipid extraction described by Folch, Lees, and Stanley (1957) was used in triplicate for the skin, pulp, and seed of the grape berry. Derivatization of the fatty acids to methyl esters (FAME) was performed by adding $500 \mu \mathrm{l}$ of HCSM (hexane/chloroform/sodium methoxide, $75 / 20 / 5, \mathrm{v} / \mathrm{v} / \mathrm{v}$ ) solution to the sample vials.

The FAME peaks were identified by comparison with FAME standards and the software library in GC-MS. An Agilent 7890 GC /5970 MS Series gas chromatograph (Agilent, Santa Clara, CA, USA) with an FID and MS and a fused (88\% - cyanopropyl) aryl-polysiloxane and high polarity capillary column (HP-88, $100 \mathrm{~m}$ x 0.25 mm, $0.20 \mu \mathrm{m}$ film (Part no: 112-88A7, Agilent, Santa Clara, CA, USA) was used. The oven temperature was initially set at $120{ }^{\circ} \mathrm{C}$ for $2 \mathrm{~min}$, and then raised to $250{ }^{\circ} \mathrm{C}$ in increments of 5 ${ }^{o} \mathrm{C} \mathrm{min}^{-1}$. The total analysis time was $45 \mathrm{~min}$. Other conditions were a split ratio of $1 / 10$, solvent delay time $12 \mathrm{~min}$, and injection volume 
Nutrient composition of 'Karaerik' grape berry |103

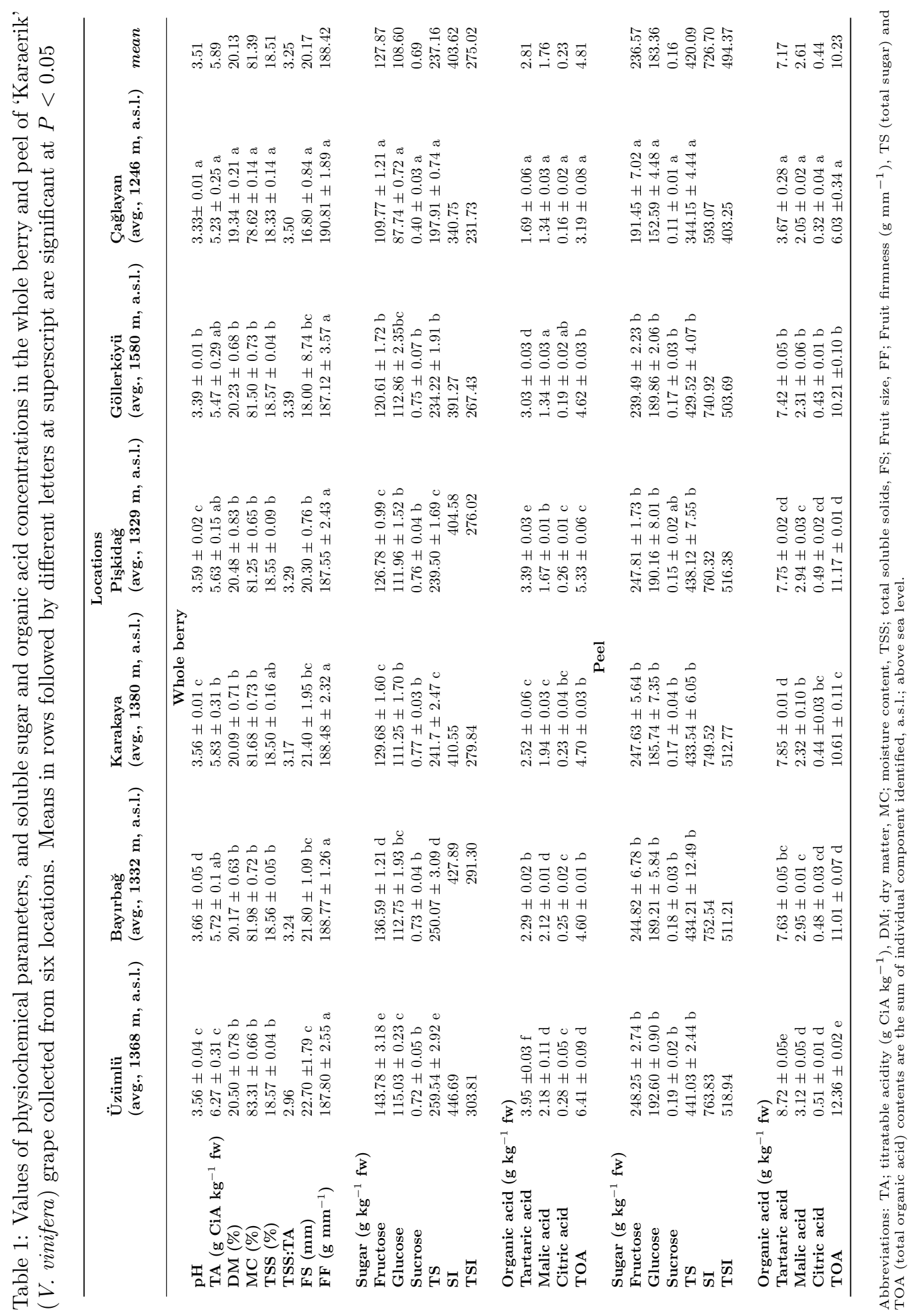

IJFS | October 2018 | Volume 7 | pages 98-116 
$104 \mid$ Kurt et al.

Table 2: Concentrations of fatty acids (\%) and minerals $\left(\mu \mathrm{g} \mathrm{g}^{-1} \mathrm{dw}\right)$ in the peel, seed and the whole grape berry of 'Karaerik' ( $V$. vinifera) collected from six locations (m, a. s. l). Analysis of variance (one-way ANOVA) was used for comparisons. Means in rows followed by different letters at superscript are significant at $P<0.05$

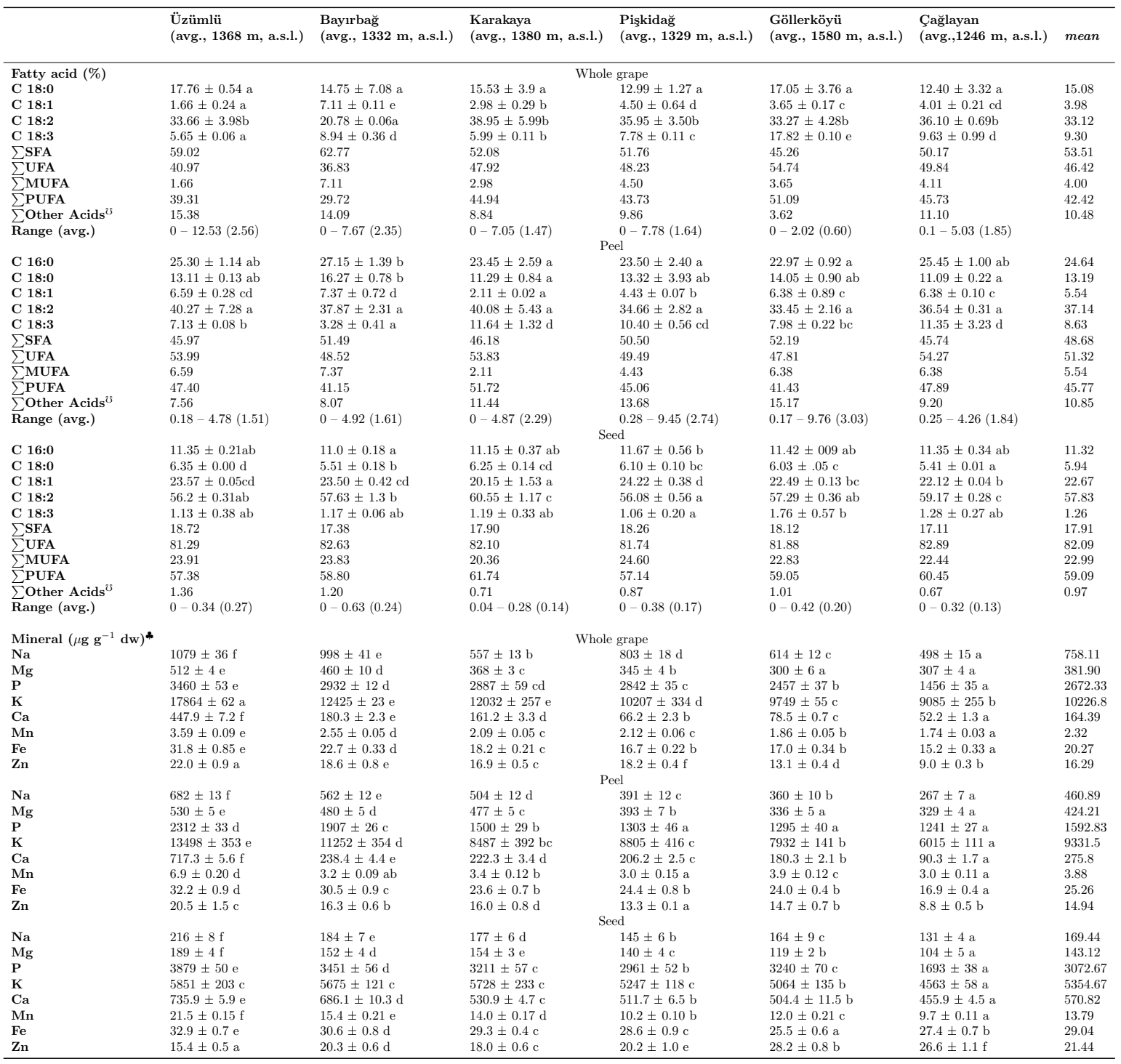

Abbreviations: C16:0; palmitic acid, C16:1; palmitoleic acid, C18:0; stearic acid, C18:1; oleic acid, C18:2; linoleic acid, C18:3; $\alpha$-linolenic acid, SFA; saturated fatty acids, UFA; unsaturated fatty acids, MUFA; monounsaturated fatty acids, PUFA; polyunsaturated fatty acids, $\mathrm{Na}$; sodium, Mg; magnesium, P; phosphorous, K; potassium, Ca; calcium, Mn; manganese, Fe; iron, Zn; zinc. , a.s.l; above sea level.

S: The other acids category is the sum of C14:0, C15:0, C16:1, C17:0, C22:0, C24:0

\&: Analytical performance; LOD, $\mathrm{mg} \mathrm{kg}^{-1}(\mathrm{Na} ; 0.12, \mathrm{Mg} ; 0.13, \mathrm{P} ; 0.17, \mathrm{~K} ; 0.13, \mathrm{Ca} ; 0.15, \mathrm{Mn} ; 0.10, \mathrm{Fe} ; 0.05, \mathrm{Cu} ; 0.08, \mathrm{Zn} ; 0.06),, \mathrm{LOQ}, \mathrm{mg}$ $\mathrm{kg}^{-1}(\mathrm{Na} ; 0.41, \mathrm{Mg} ; 0.45, \mathrm{P} ; 0.57, \mathrm{~K} ; 4.3, \mathrm{Ca} ; 4.9, \mathrm{Mn} ; 0.34, \mathrm{Fe} ; 0.16, \mathrm{Zn} ; 0.19$,$) , RSD, \% Na; 2.7, Mg; 2.7, P; 3.1, K; 3.1, Ca; 3.6, Mn; 2.5,$ $\mathrm{Fe} ; 0.9, \mathrm{Zn} ; 1.9)$. 
$1 \mu \mathrm{L}$. An injection system with auto sampler was used.

\subsection{Element analysis}

Briefly, $0.5 \mathrm{~g}$ dried finely powdered grape sample (deseeded whole grape, skin and seed) at $0.1 \mathrm{mg}$ sensitivity was weighed into the Teflon vessels of a microwave digestion system (A Milestone START D, Sorisole, Italy). Next, $6 \mathrm{~mL}$ of concentrated $\mathrm{HNO}_{3}$ and $2 \mathrm{~mL}$ of $\mathrm{H}_{2} \mathrm{O}_{2}$ were added. The content of the vessels was digested under microwave irradiation at 45 bar pressure, as described elsewhere (Bulut et al., 2008; Duran et al., 2007). After digestion, the limpid solutions were made up to $50 \mathrm{~mL}$ with ultrapure water, and finally the solutions were analyzed by ICPMS to determine the element content of the samples. The limpid solutions were analyzed with an Agilent 7700 x ICP-MS device (Santa Clara, California, USA) equipped with a third-generation Octopole Reaction System $\left(\mathrm{ORS}^{3}\right)$ using helium gas under conditions recommended by the manufacturer.

In order to corroborate the accuracy of the ICPMS method combined with the microwave digestion, spiked/recovery tests and analysis of a certified standard reference material, CRM NIES No. 7 Tea Leaves, were performed using the same method. Satisfactory results were achieved at the end of the accuracy test. The analytical characteristics of the method were also determined with the parameters LOD (limit of detection), LOQ (limit of quantification) and RSD (relative standard deviation). In order to determine the LOD and LOQ of each element, the standard deviations of the results obtained by measuring 20 blank solutions with ICP-MS method were calculated. Values three- and 10-fold greater than the standard deviation were adopted as LOD and LOQ, respectively. In order to determine the RSD value of each element, which represents the precision, the method was repeated 10 times for analyzing solutions containing a fixed amount of each element. The RSD values were calculated by dividing the standard deviation of each element by the mean value (Bulut et al., 2008). The results are shown in Table 2.

\section{7 $\quad$ Statistical Analysis}

All extractions and analyses were performed in triplicate $(\mathrm{n}=3$, mean) from harmonized triplicate samples, and the data are presented as mean \pm pooled standard deviation. The data given in Table 1 and 2 were compared using one-way analysis of variance (ANOVA) and Duncan's Multiple Range test (IBM SPSS Statistics V22.0) at significance level of $P<0.05$. The mean data were also subjected to Pearson correlation $(r)$ using the same software at significance levels of $P<0.01$ or 0.05 . A statistical software package (XLSTAT version 2014.6) using ADDINSOFT (Damrémont, Paris, France) was employed to perform the Principal Component Analysis (PCA) on Microsoft Office Excel 2010 .

\section{Results and Discussions}

\subsection{Physicochemical parameters of the 'Karaerik' grape berry}

The values for physicochemical parameters were strongly positively or negatively correlated with the concentrations of sugars and organic acids in the whole grape berry and the peel sampled from grape berries in the six locations in the district of Üzümlü and the surrounding area (Fig. 1, Table 1$)(P<0.01,0.05$, Table 3$)$. The results show that the grape berries sampled from Çağlayan differed significantly $(P<0.01$ or 0.05$)$ from those from the other five locations, exhibiting lower physicochemical parameter values and concentrations of sugars and acids. The $\mathrm{pH}$ value in the berry of the 'Karaerik' grape agrees rather well with the average values for 101 grape berries previously reported (Akpınar \& Yiğit, 2011; Eyduran, Akin, Ercisli, Eyduran, \& Maghradze, 2015; Karasu et al., 2016; Rolle, Giacosa, Gerbi, Bertolino, \& Novello, 2013; Xu et al., 2017; Yamamoto et al., 2015). The TA in the present grape berry was also in good agreement with ranges reported for 33 grape berries (avg. 4.3, range $0.3-11.6 \mathrm{CAE} \mathrm{g} \mathrm{kg}^{-1} \mathrm{fw}$ ) in various studies (Ejsmentewicz et al., 2015; Ochmian et al., 2013; Pavlousek \& Kumsta, 2011; Rolle et al., 2013; Yamamoto et al., 2015). However, data re- 
ported for dry matter (avg. 26.1\%, range 22.2 - 28.8) and moisture (avg. 92.3\%, range 85.6 $98.6)$ contents in eight grape berry cvs are not in agreement with those reported by several authors (Karasu et al., 2016; Kurt et al., 2017; Ochmian et al., 2013; Ozcan \& Al Juhaimi, 2017). Notably, Lijavetzky et al. (2012) also reported a low DM content (avg. 15.9\%) in 'Muscat Hamburg' grape cultivar. In addition to these values, the TSS, FS and FF values of the 'Karaerik' grape berry in the present study exhibited good agreement with the findings for 104 grape cvs (avg. 18.2 , range $10.9-25.7$, avg. 16.4 , range 12.1 - 26.6, avg. 276.3, range $69.4-605 \mathrm{~g} \mathrm{~mm}^{-1}$, respectively) described in other studies (Conner, 2013; Ochmian et al., 2013; Ejsmentewicz et al., 2015; Yamamoto et al., 2015; Eyduran et al., 2015; Xu et al., 2017).

\subsection{Soluble sugar composition of the 'Karaerik' grape berry}

Fructose was the dominant soluble sugar, with a mean value of $236.57 \mathrm{~g} \mathrm{~kg}^{-1}$ fw (range 191.45 to $248.25)$, in the peel berry and of $127.87 \mathrm{~g} \mathrm{~kg}^{-1}$ fw (range 109.77 to 143.78 ) in the whole grape, followed by glucose (avg. 183.36; range 152.9 192.60 and 108.60 ; range $87.74-115.03$ ) and the minor soluble sugar sucrose (avg. 0.16 and $0.69 \mathrm{~g}$ $\mathrm{kg}^{-1} \mathrm{fw}$ ). Among the six locations in this study, only the grape berries sampled from Çağlayan differed significantly $(P<0.01$ or 0.05$)$ with their low concentrations of soluble sugars, while the remaining five locations exhibited similar concentrations at high levels, the difference between them being statistically insignificant (Table 1). Fructose and glucose have been identified as the major soluble sugars in grape berries, as in the 'Karaerik' grape berry, while sucrose and other sugars are rarely found in $V$. vinifera and its hybrids with $V$. labrusca or others, as reviewed by Kurt et al. (2017). Estimated concentrations of fructose (avg. $83.4 \mathrm{~g} \mathrm{~kg}^{-1} \mathrm{fw}$; range $47.4-155.5$ ) and glucose (avg. $88.2 \mathrm{~g} \mathrm{~kg}^{-1} \mathrm{fw}$; range $64-$ 164.7) in a large number of grape berries have indicated wide variations in content (Eyduran et al., 2015; Karasu et al., 2016; Kurt et al., 2017; Liu, Wu, Fan, Li, \& Li, 2006; Liang et al., 2011; Pavlousek \& Kumsta, 2011; Sousa et al., 2014;
Topalovic \& Mikulic-Petkovsek, 2010). A similar pattern was observed in sugar profiles in berries of the 'Karaerik' grape to those reported for the above citations. A low level of sucrose in grape berries ( V. vinifera x V. labrusca) (Kurt et al., 2017) has also very recently been confirmed in the grape berry in the present study (Karaerik).

\subsection{Organic acid composition of the 'Karaerik' grape berry}

The major organic acid in the grape berry was tartaric acid, the levels of which varied between 3.67 and $8.72 \mathrm{~g} \mathrm{~kg}^{-1} \mathrm{fw}$ (avg. 7.17) in the peel and 1.69 and $3.95 \mathrm{~g} \mathrm{~kg}^{-1} \mathrm{fw}$ (avg. 2.81) in the whole grape berry over the six sampling locations. This was followed by malic acid (avg. 2.61 ; range $2.05-3.12$ and $1.76 ; 1.34-2.18$, respectively). Similar to the sugar concentrations, berries sampled from Çağlayan had significantly $(P<0.01$ or 0.05$)$ lower organic acid concentrations than berries from the other five locations (Table 1). The minor acid was citric acid, as reported earlier elsewhere (Kurt et al., 2017) for grape berries, the concentration of which averaged 0.44 and $0.23 \mathrm{~g} \mathrm{~kg}^{-1} \mathrm{fw}$ in the peel and the whole grape berry, respectively. Most grape berries are reported to contain tartaric acid as the major organic acid (Mpelasoka, Schachtman, Treeby, \& Thomas, 2003). A compilation of data for 46 grape berry cvs or varieties revealed an average of $4.41 \mathrm{~g} \mathrm{~kg}^{-1} \mathrm{fw}$ (range $1.40-12.71$ ) of tartaric acid and $2.21 \mathrm{~g} \mathrm{~kg}^{-1} \mathrm{fw}$ (range 0.97 5.19) of malic acid (Eyduran et al., 2015; Liu et al., 2006; Pavlousek \& Kumsta, 2011; Rolle et al., 2013; Topalovic \& Mikulic-Petkovsek, 2010). Our findings for the present grape (Karaerik) were also in agreement with the ranges previously reported in the literature. Some authors have reported quite low citric acid concentrations in grape berries (29 cvs) (avg. $0.26 \mathrm{~g} \mathrm{~kg}^{-1} \mathrm{fw}$; range 0.04 -0.96), (Kurt et al., 2017; Pavlousek \& Kumsta, 2011; Rolle et al., 2013). Kurt et al. (2017), Pavlousek and Kumsta (2011), Rolle et al. (2013) and others have reported complete absence of citric acid (Eyduran et al., 2015; Liu et al., 2006). We determined approximately the same concentration of citric acid in the present grape berry (avg. $0.23 \mathrm{~g} \mathrm{~kg}^{-1} \mathrm{fw}$, range $0.16-$ 
Nutrient composition of 'Karaerik' grape berry $\mid 107$

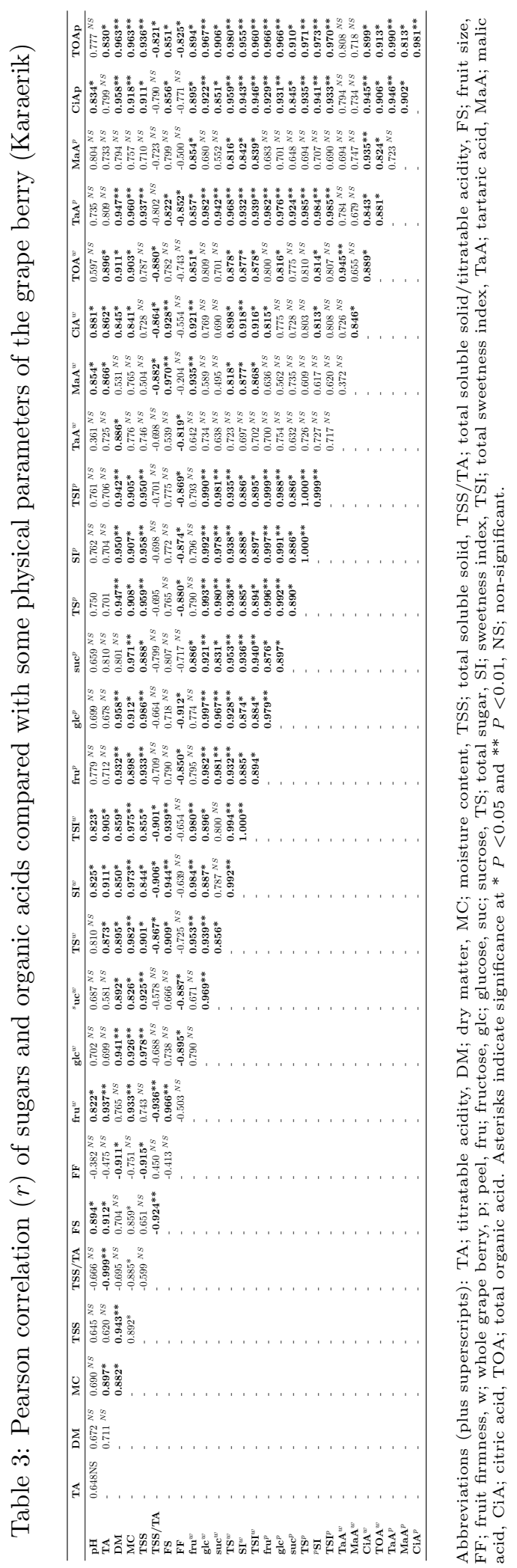

\begin{tabular}{l|l|l|l} 
IJFS | October 2018 | Volume 7 & pages 98-116
\end{tabular} 
$108 \mid$ Kurt et al.

$0.28)$.

Sugars and organic acids have been described as an important key factor in evaluating organoleptic properties in grape berries. In the present study, sugars and organic acids were closely and significantly correlated (either positively or negatively) with physicochemical parameters and sampling locations (range, $r=0.813-1.000, P$ $<0.01$ or 0.05 , see Table 3 ).

\subsection{Fatty acid composition of the 'Karaerik' grape berry}

Linoleic acid, with average concentrations of $33.12 \%$ in the whole grape berry, $37.14 \%$ in the peel and $57.83 \%$ in the seed, was the most abundant fatty acid in the 'Karaerik' grape. Concentrations of "other acids", as the minor acids, (representing the sum of myristic acid, pentadecanoic acid, palmitoleic acid margaric acid, behenic acid, and lignoceric acid), averaged $10.48 \%$ in the whole grape berry, $10.85 \%$ in the peel and $0.97 \%$ in the seed. The highest C18:2 had been $40.27 \%$ in the peel of sampled berries from Üzümlü and $60.55 \%$ in the seed of sampled berries from Karakaya (Table 2). Table 4 clearly indicates that the fatty acids were largely insignificantly correlated with physicochemical parameters and sampling locations, although there were possible strong positive or negative correlations within the physicochemical parameters and the sum of fatty acids (range $r=-0.817-1.000$, $P<0.01$ or 0.05$)$. In general, fatty acid composition in grape berries, except for seeds, has rarely been described. More recently, fatty acid changes during berry maturation and ripening of the 'Isabel' grape have been well studied (Kurt et al., 2017). A notable large variation in concentrations of major saturated (C16:0; avg. 9.6\%, range 7.1 - 8.24, C18:0; avg. 4.5, range 2.4 6.5 ) and unsaturated (C18:1; avg. 20.6\%, range 13.4 - 32.3, C18:2; avg. $63.9 \%$, range 47.3 70.7) fatty acids has been observed among 44 grape berry cvs or varieties (i.e. wine or table grapes), in agreement with the findings for 'Karaerik' in the present study, by some authors (Akin \& Altindisli, 2011; Al Juhaimi, Gecgel, Gulcu, Hamurcu, \& Ozcan, 2017; Kurt et al., 2017; Shiozaki \& Murakami, 2016).

\subsection{Mineral composition of the 'Karaerik' grape berry}

Concentrations of eight elements (Table 2) in the present grape berry varied significantly $(P<$ $0.05)$ and were strongly positively or negatively correlated (range, $r=0.813-0.999, P<0.01$ or 0.05 , Table 5) with the physicochemical parameters or sampling locations. In general, mineral concentrations were higher in berries sampled from Üzümlü than in those from Çağlayan (the lowest concentration). Potassium was the most abundant mineral in the whole grape berry (avg. 10,226.8 $\mu \mathrm{g} \mathrm{g}^{-1} \mathrm{dw}$ ), the peel (avg. 9331.5 $\mu \mathrm{g} \mathrm{g}^{-1} \mathrm{dw}$ ) and the seed (avg. $5354.67 \mu \mathrm{g} \mathrm{g}^{-1}$ $\mathrm{dw}$ ), followed by phosphorus (P, avg. 2672.33

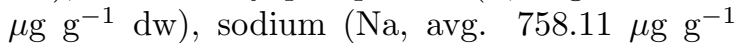
$\mathrm{dw}$ ) and magnesium (Mg, avg. $381.90 \mu \mathrm{g} \mathrm{g}^{-1}$ $\mathrm{dw})$. 'Karaerik' grapes contained considerable amounts of calcium (avg. $164.39 \mu \mathrm{g} \mathrm{g}^{-1} \mathrm{dw}$ ) in the whole berry, in the peel (avg. $275 \mu \mathrm{g} \mathrm{g}^{-1} \mathrm{dw}$ ) and in the seed (avg. $570.82 \mu \mathrm{g} \mathrm{g}^{-1} \mathrm{dw}$ ). Concentrations of iron and zinc in the present grape berry were also high and comparable (avg. 20.27 and $16.29 ; 25.26$ and $14.94 ; 29.04$ and 21.44, $\mu \mathrm{g} \mathrm{g}^{-1} \mathrm{dw}$, respectively, Table 4). K (potassium) was also the major element in the "Shiraz' grape cultivar, with concentrations of 4380 , 3660 and $3360 \mathrm{~g}^{-1} \mathrm{dw}$ in the skin, seed and peel, respectively, (Rogiers, Greer, Hatfield, Orchard, \& Keller, 2006). Earlier reported concentrations (avg. $\mathrm{g} \mathrm{kg}^{-1} \mathrm{fw}$ ) of the first three major elements in grapes were 958.98 (range 10.80 to 3870 ) for potassium, 56.2 (range 095 to 92.3) for calcium and 39 (range $0.87-190$ ) for phosphorus (Kurt et al., 2017; Rogiers et al., 2006; Sousa et al., 2014). Our findings are generally in agreement with the given citations regarding the composition of minerals in grape berries. In terms of tissue, most of the phosphorus accumulated in the seeds of grape berries, as concluded previously by Rogiers et al. (2006) and Kurt et al. (2017), and this was also confirmed in the seeds of the grape berry in the present study. It was determined with the present study that sampling locations having different soil characteristics affected the mineral composition of the grape berry. Güneş, Köse, and Turan (2015) have studied the effect of different boron concentrations on nutrient uptake 
Nutrient composition of 'Karaerik' grape berry | 109

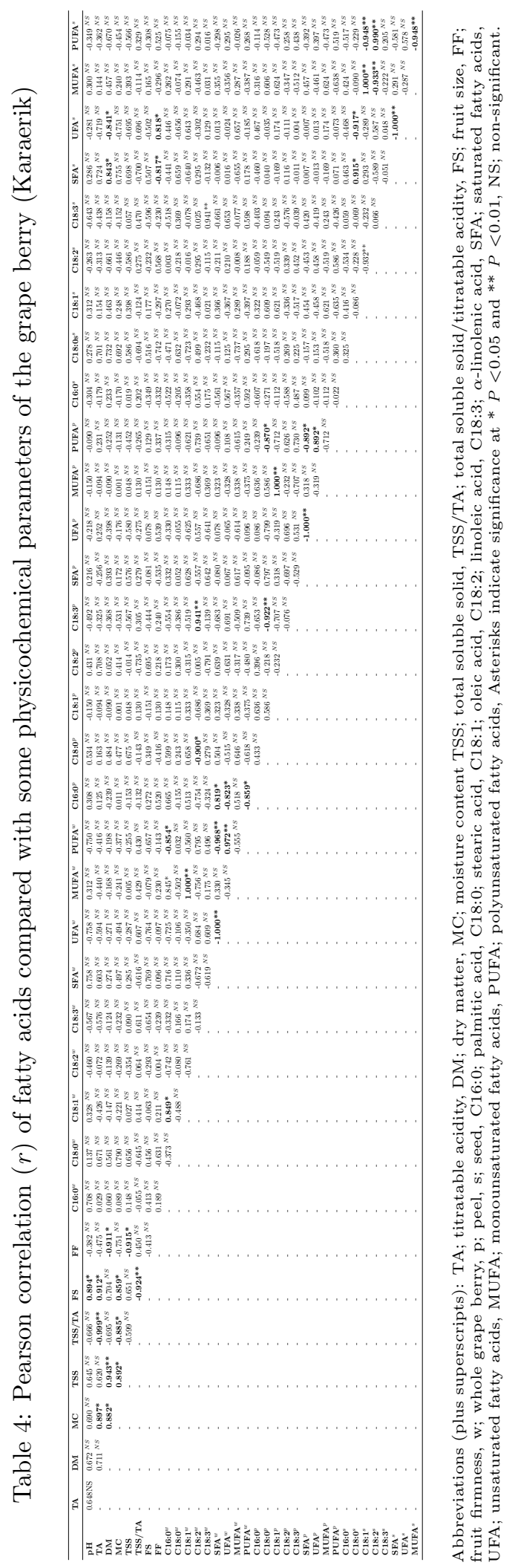

IJFS | October 2018 | Volume 7 | pages 98-116 
of the same grapevine (Karaerik) in Üzümlü location and reported more or less the same findings, agreeing with those reported in the present study.

We have assumed that the higher nutrient content in the present grape berry, 'Karaerik', results from the soil characteristics and the unique microclimate in the district of Üzümlü. The district is located in the Esence Mountains in the upper Euphrates in the west of the Eastern Anatolian region, which covers a large part of the north of the Erzincan plain, with an area of 410 $\mathrm{km}^{2}$ and a generally mountainous and rugged relief structure. Alluvium, hydromorphic alluvium and coluvial soils are common in the valleys and surrounding areas, while litosols are dominant in mountainous areas. Due to its lithological structure, land extruded from ophiolitic rocks, which are very prone to erosion and are subjected to intense tectonic movements, has acquired a lithozolic characteristic as a result of extreme soil erosion. The climate is terrestrial with significant summer-winter temperature differences, involving cold winters and short but quite hot summers due to factors such as altitude, distance from the sea and especially the Siberian High Pressure Center. The severity of continentality is evident, and clearly manifests itself in the region's temperature, pressure and precipitation regimens, in the snow cover inhabitation period, and the upper limit of permanent snow and forest. The region generally receives rainfall of over $500 \mathrm{~mm}$, except for in depressions, including the Erzincan plains. However, on the relatively low slopes of the mountains and on brown ground on the high plateau plains, 'Karaerik' breeding is carried out in an uncommon microclimate (Akpınar \& Yiğit, 2011; Güner \& Aslan, 2012).

\subsection{Principal component analysis (PCA) and Pearson correlation $(r)$}

Analysis of the sugars and organic acids (Fig. 2A) and minerals (Fig. 2C) compared between sampling locations and the measured physicochemical parameters revealed that two principal components (PCs) accounted for 92.75\% (PC1: $83.96 \%$ and $\mathrm{PC} 2: 8.79 \%$, Fig. 2A) of sugars and organic acids and $90.05 \%$ (PC1: $80.48 \%$ and PC2: $9.57 \%$, Fig. 2D) of minerals. Data exhibited strong positive loadings at the right upper and lower quadrants on PC1 of each PC, distinguishing the Karakaya, Bayırbağ, Üzümlü and Pişkidağ locations for the sugar and organic acid concentrations, and the Üzümlü, Bayırbă̆ and Karakaya locations for the mineral concentrations. They were also closely associated and positively or negatively strongly correlated $(P<0.01$ or 0.05$)$ with most of the physicochemical parameters measured in the grape berry. The remaining three locations, Çağlayan, Göllerköyü and Pişkidağ, exhibited strong negative loadings on their PCs, 2 at the lower and upper left quadrants, associating less and correlating only with FF value, the ratio of TSS:TA and the zinc concentration. When compared, the berries sampled from Çağlayan (1246 m, a.s.l.) exhibited a noticeable altitude effect and contained the lowest concentration of sugars, organic acids and minerals, and this site was thus easily distinguished from the other five altitudes/locations (Fig. 2A,C).

Figure 2B shows $\mathrm{PCs}$ of the data for fatty acids in the berry. The PCA of the fatty acids explained a low total variation $(61.82 \%)$, where $\mathrm{PC} 1$ accounted for $34.15 \%$ of the variance and $\mathrm{PC} 2$ for $27.67 \%$ (Fig. 2B). The association or correlation seen in the case of sugars and organic acids or minerals was not clearly observed for the fatty acids. The fatty acids could not be distinguished on basis of the PCs, and were not associated or correlated with the measured physicochemical parameters or sampling locations; to be more precise, they were cluttered.

\subsection{Agglomerative hierarchical clustering (AHC) of the nutrients in the black grape berry}

The dendrogram (Fig. 2D) shows that the sugars and organic acids of the berry sampled from six locations were homogeneous and that the Çağlayan location (cluster I), which had low nutrient concentrations, exhibited major differences from the other five locations (Üzümlü, Göllerköyü, Pişkidağ, Bayırbağ and Karakaya) 
Nutrient composition of 'Karaerik' grape berry |111

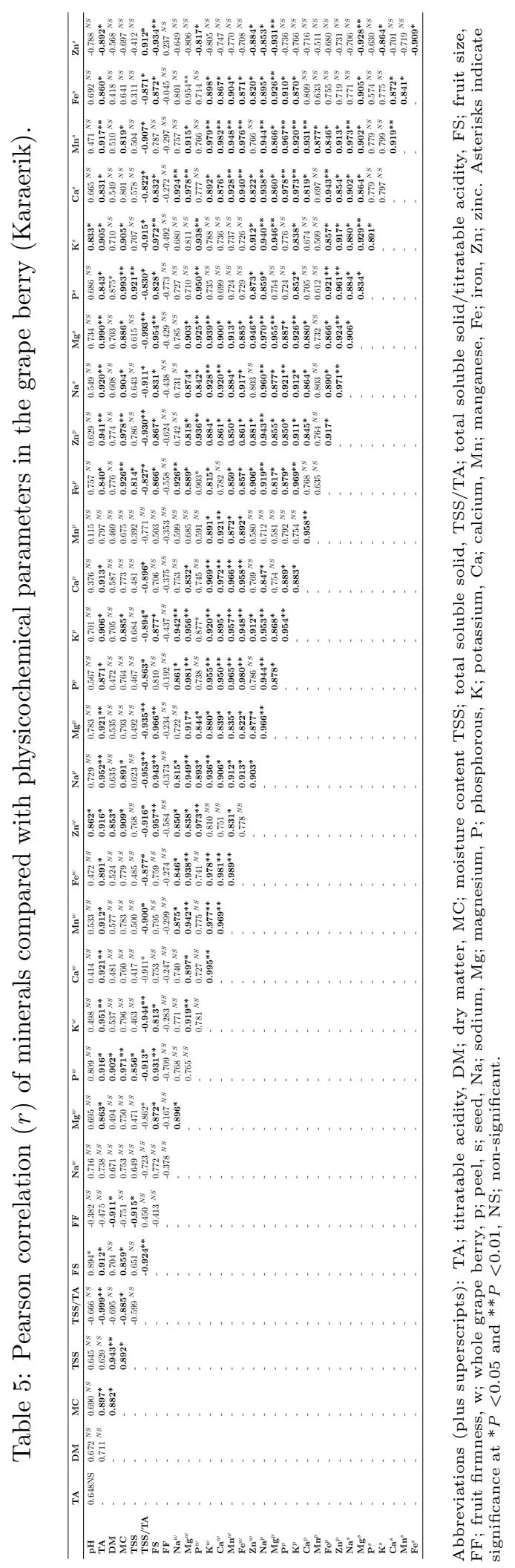

\begin{tabular}{l|l|l|l} 
IJFS | October 2018 | Volume 7 & pages 98-116
\end{tabular} 
$112 \mid$ Kurt et al.
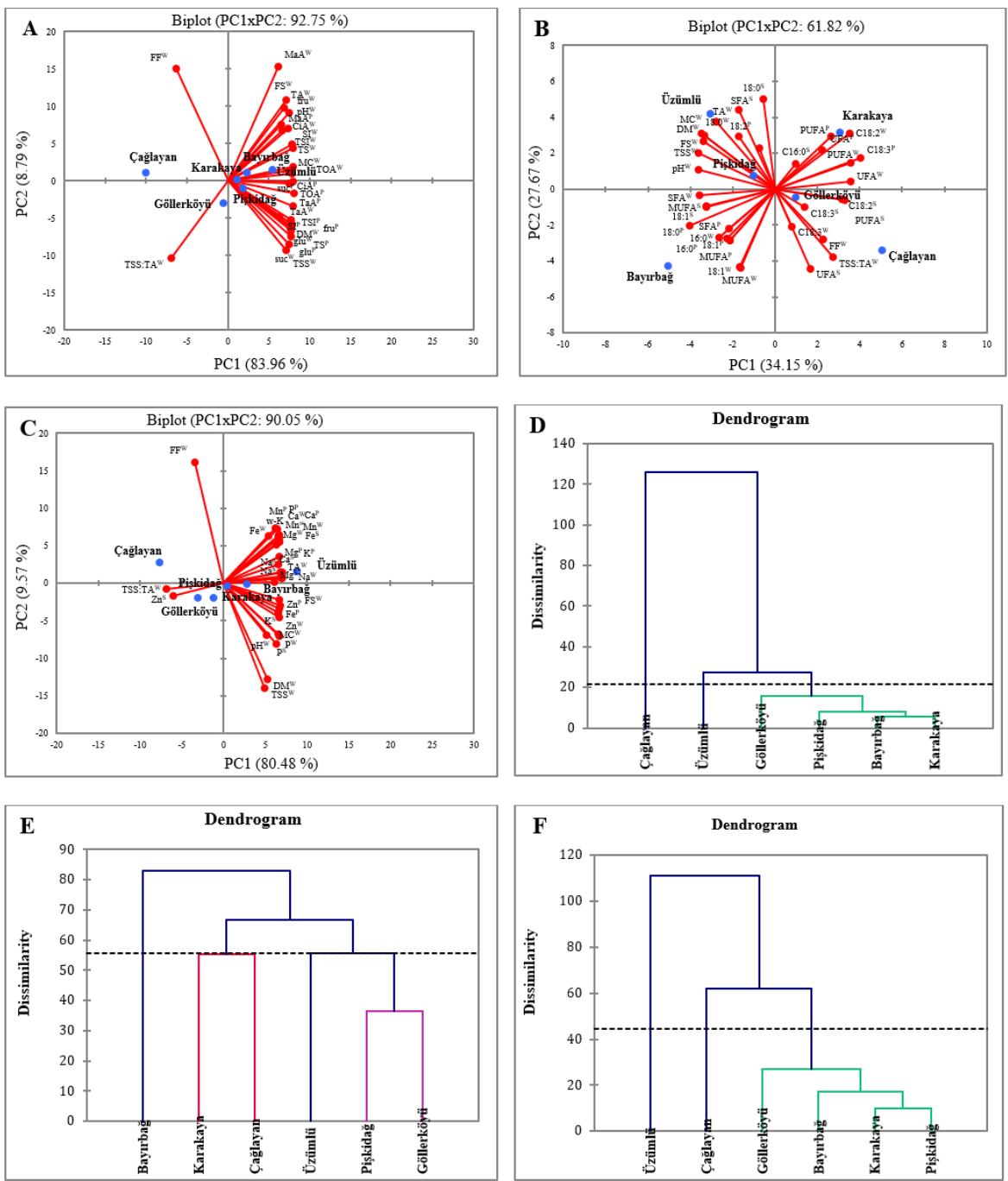

Figure 2: Bi-plot PCA of nutrients in the berry of 'Karaerik' grapes sampled from six locations in the district of Üzümlü and its surroundings

(A) sugars and organic acids, (B) fatty acids, (C) minerals in the peel, whole grape berry and seed. Agglomerative hierarchical clustering (AHC) for sugar and organic acids (D), fatty acids (E) and minerals (F) in the peel, whole grape berry and seed. Abbreviations: w; whole grape berry, p; peel, MC; moisture content, DM; dry matter, FS; fruit size, fru; fructose, glu; glucose, suc; sucrose, TS; total sugar, TSS; total soluble solids, TA; titratable acidity, TaA; tartaric acid, MaA; malic acid, CiA; citric acid, TOA; total acid (whole berry + pulp), SI; sweetness index, TSI; total sweetness index 
(cluster II), with their high nutrient concentrations. The grapes sampled from Bayurbağ and Karakaya (cluster III) were capable of being clustered within a short hierarchical distance as a third cluster (III), indicating that they had similar nutrient profiles.

As shown in Fig. 2E, the fatty acids were irregularly clustered, as in the case of the PCs (Fig. 2B). The Bayırbağ location (cluster I) differed significantly from the other five locations. It may be suggested that the profiles of fatty acids in the grape berry sampled from Bayırbağ are significantly different from those in grape samples from the remaining five locations. The grape berry samples from Karakaya and Çăglayan (cluster II) exhibited a similar fatty acid fingerprint. The Üzümlü location (cluster III) was capable of being clustered within a long hierarchical distance at a similar concentration to the Karakaya and Çağlayan sites (cluster II). Pişkidağ and Göllerköyü (cluster IV), with a short hierarchical distance, exhibited similar concentrations of fatty acids, but rather lower than those of Üzümlü.

Three main groups and several subgroups within each group were considered in terms of the mineral/elements among the concentrations and the physical parameters measured. Cluster I included Üzümlü, interestingly clustered within a long hierarchical distance and differing from the grape berries sampled from the remaining five locations. Çağlayan (cluster II), with its low mineral concentrations, was capable of being clustered within a moderate hierarchical distance, exhibiting greater differences from the locations Göllerköyü, Bayırbağ, Karakaya and Pişkidă̆ (cluster III). The third cluster (cluster III) was capable of division into four subgroups (Fig. 2F). In their review, Mpelasoka et al. (2003) and Lasik (2013) emphasized that potassium is the major cation in grape berry or juice, and that high potassium juice reduces free acids and increases overall $\mathrm{pH}$. They also reported that tartaric acid is a significantly stronger acid than malic acid, and at similar values of total acidity, a lower tartrate:malate (TA:MA) ratio may therefore result in a less acidic $\mathrm{pH}$. It has also been reported that high malate enhances malolactic fermentation (Mpelasoka et al., 2003; Abrahamse \& Bartowsky, 2012; Lasik, 2013). This sec- ondary fermentation is carried out by many lactic acid bacteria and may have either positive or negative impacts on the organoleptic quality of wines. This necessitates the use of commercial lactic acid bacteria starter-cultures to control malolactic fermentation (Abrahamse \& Bartowsky, 2012; Lasik, 2013). Tartrate also bestows a crisp and fresh acidic taste to wine and is therefore preferred to malate. During winemaking, high potassium increases the precipitation of tartrate in salt and hence reduces free tartrate. High potassium can therefore lead to a reduced TA:MA ratio, which is undesirable for high quality wines, as earlier reviewed by Mpelasoka et al. (2003). In the present study, the TA:MA ratio was 1.59 and the highest $\mathrm{pH}$ was 3.7 (avg., 3.5, over the six locations) in berries of the 'Karaerik' grape. However, berries of the 'Isabel' grape had a 0.77 TA:MA ratio and 3.1 $\mathrm{pH}$ in ripe and overly ripe berries (Kurt et al., 2017).

\section{Conclusion}

In conclusion, this study provides the first data in the literature concerning the nutrient profile in berries of the new grape cultivar 'Karaerik' among the various $V$. vinifera grapes. Sugars, organic acids and minerals quantified separately in the whole berry and the peel exhibited strong positive and negative correlations with the measured physicochemical parameters and sampling locations, although the fatty acids were not so correlated. Berries sampled from Üzümlü, the best potential growing location for the grape, contained higher concentrations of nutrients than berries from Cağlayan. Our findings represent important data for viticulturists and for the food science and technology industries. The berry of the grape investigated in this study has a unique taste and flavor that make it very popular with consumers. These properties distinguish the grape from $V$. vinifera fruits. We therefore conclude that the 'Karaerik' grape should be given "protected" status. More comprehensive nutritional studies are now needed to obtain deeper insights into this and other quality parameters and to open the possibility of establishing new vineyards to improve the grape in breeding pro- 
grams without destroying the present form in terms of biological diversity conservation. Further studies are also needed to investigate the antioxidant properties and phenolic profile of the grape berry. An ongoing project investigating the detailed phenolic profiles of the berry supplemented with antioxidant properties is currently being performed in our laboratory.

\section{Acknowledgements}

Financial support for this study was provided by the Scientific and Technological Research Council of Turkey (TUBITAK- Project number: 115Z365).

\section{References}

Abrahamse, C. E. \& Bartowsky, E. J. (2012). Timing of malolactic fermentation inoculation in shiraz grape must and wine: influence on chemical composition. World Journal of Microbiology \& Biotechnology, 28(1), 255-265. doi:10.1007/s11274-0110814-3

Akin, A. \& Altindisli, A. (2011). Determination of fatty acid composition and lipid content of some grape cultivar seeds in Turkey. Biyoloji Bilimleri Araştırma Dergisi, 4 (2), 1315.

Akpinar, E. \& Yiğit, D. (2011). Ekolojik faktörlerin karaerik üzüm çeşidi yetiştiriciliğine etkileri. Doğu Coğrafya Dergisi, 11 (16).

Al Juhaimi, F., Gecgel, U., Gulcu, M., Hamurcu, M., \& Ozcan, M. M. (2017). Bioactive properties, fatty acid composition and mineral contents of grape seed and oils. South African Journal of Enology and Viticulture, 38(1), 103-108.

Association of Official Agricultural Chemists. (2003). Official Methods of Analysis of AOAC International. 17th ed. 2nd revision. Gaithersburg, USA.

Association of Official Agricultural Chemists. (2011). Official Methods of Analysis of AOAC International. 18th ed. Gaithersburg, USA.
Ayaz, F., Colak, N., Kurt, A., Akpinar, E., Gomez-Alonso, S., \& Hermosin-Gutierrez, I. (2017). First evidence of the occurrence of feruloyl derivatives of anthocyanins in Vitis vinifera black grape cultivar: the Turkish 'Karaerik' grape. Paper presented at 10th Symposium: In Vino Analytica Scientia (IVAS), Analytical Chemistry for Wine, Brandy and Spirits, Universidad de Castilla la Mancha, Spain.

Bulut, V. N., Duran, C., Gundogdu, A., Soylak, M., Yildirim, N., \& Elci, L. (2008). A new approach to separation and preconcentration of some trace metals with co-precipitation method using a triazole. Talanta, 76(2), 469-474. doi:10.1016/j . talanta.2008.03.040

Conner, P. J. (2013). Instrumental textural analysis of muscadine grape germplasm. Hortscience, 48(9), 1130-1134.

Duran, C., Senturk, H. B., Gundogdu, A., Bulut, V. N., Elci, L., Soylak, M., ... Uygur, Y. (2007). Determination of some trace metals in environmental samples by flame aas following solid phase extraction with amberlite xad-2000 resin after complexing with 8-hydroxyquinoline. Chinese Journal of Chemistry, 25(2), 196-202. doi:10.1002/ cjoc. 200790040

Ejsmentewicz, T., Balic, I., Sanhueza, D., Barria, R., Meneses, C., Orellana, A., ... Campos-Vargas, R. (2015). Comparative study of two table grape varieties with contrasting texture during cold storage. Molecules, 20(3), 3667-3680. doi:10.3390/ molecules20033667

Eyduran, S. P., Akin, M., Ercisli, S., Eyduran, E., \& Maghradze, D. (2015). Sugars, organic acids, and phenolic compounds of ancient grape cultivars (Vitis vinifera L.) from Igdir province of Eastern Turkey. Biological Research, 48. doi:10.1186/07176287-48-2

Ferretti, G., Turco, I., \& Bacchetti, T. (2014). Apple as a source of dietary phytonutrients: bioavailability and evidence of protective effects against human cardiovascular disease. Food and Nutrition Sciences, 05, 1234-1246. 
Folch, J., Lees, M., \& Stanley, G. H. S. (1957). A simple method for the isolation and purification of total lipides from animal tissues. Journal of Biological Chemistry, 226, 497509.

Güner, A. \& Aslan, S. (2012). Türkiye bitkileri listesi:(damarl bitkiler). Nezahat Gökyigit Botanik Bahçesi Yayınları.

Günes,, A., Köse, C., \& Turan, M. (2015). Yield and mineral composition of grapevine ( $\mathrm{Vi}$ tis vinifera L. cv. Karaerik) as affected by boron management. Turkish Journal of Agriculture and Forestry, 39(5), 742-752. doi:10.3906/tar-1412-13

Hyson, D. A. (2011). A comprehensive review of apples and apple components and their relationship to human health. Advances in Nutrition, 2(5), 408-420. doi:10.3945/an. 111.000513

Karasu, S., Baslar, M., Karaman, S., Kilicli, M., Us, A. A., Yaman, H., \& Sagdic, O. (2016). Characterization of some bioactive compounds and physicochemical properties of grape varieties grown in Turkey: thermal degradation kinetics of anthocyanin. Turkish Journal of Agriculture and Forestry, 40(2), 177-185. doi:10.3906/tar-1502-38

Kurt, A., Torun, H., Colak, N., Seiler, G., Hayirlioglu-Ayaz, S., \& Ayaz, F. A. (2017). Nutrient profiles of the hybrid grape cultivar 'Isabel' during berry maturation and ripening. Journal of the Science of Food and Agriculture, 97(8), 2468-2479. doi:10. $1002 /$ jsfa. 8061

Lasik, M. (2013). The application of malolactic fermentation process to create good-quality grape wine produced in cool-climate countries: a review. European Food Research and Technology, 237(6), 843-850. doi:10 . 1007/s00217-013-2083-X

Liang, Z., Sang, M., Fan, P., Wu, B., Wang, L., Duan, W., \& Li, S. (2011). Changes of polyphenols, sugars, and organic acid in 5 vitis genotypes during berry ripening. Journal of Food Science, 76(9), C1231C1238. doi:10.1111/j. 1750 - 3841. 2011. 02408.x

Lijavetzky, D., Carbonell-Bejerano, P., Grimplet, J., Bravo, G., Flores, P., Fenoll, J., ... Martinez-Zapater, J. M. (2012). Berry flesh and skin ripening features in Vitis vinifera as assessed by transcriptional profiling. Plos One, 7(6). doi:10.1371/journal. pone. 0039547

Liu, H.-F., Wu, B.-H., Fan, P.-G., Li, S.-H., \& Li, L.-S. (2006). Sugar and acid concentrations in 98 grape cultivars analyzed by principal component analysis. Journal of the Science of Food and Agriculture, 86(10), 15261536. doi:10.1002/jsfa. 2541

Liu, R. H. (2013). Dietary bioactive compounds and their health implications. Journal of Food Science, 78(1), A18-A25. doi:10 . 1111/1750-3841.12101

Magwaza, L. S. \& Opara, U. L. (2015). Analytical methods for determination of sugars and sweetness of horticultural products-a review. Scientia Horticulturae, 184, 179192. doi:10.1016/j.scienta.2015.01.001

Mikulic-Petkovsek, M., Schmitzer, V., Slatnar, A., Stampar, F., \& Veberic, R. (2012). Composition of sugars, organic acids, and total phenolics in 25 wild or cultivated berry species. Journal of Food Science, 77(10), C1064-C1070. doi:10.1111/j.17503841.2012.02896.x

Mpelasoka, B. S., Schachtman, D. R., Treeby, M. T., \& Thomas, M. R. (2003). A review of potassium nutrition in grapevines with special emphasis on berry accumulation. Australian Journal of Grape and Wine Research, 9(3), 154-168. doi:10.1111/j.17550238.2003.tb00265.x

Ochmian, I., Angelov, L., Chełpiński, P., Stalev, B., Rozwarski, R., \& Dobrowolska, A. (2013). The characteristics of fruits morphology, chemical composition and colour changes in must during maceration of three grapevine cultivars. Journal of Horticultural Research, 21(1), 71-78. doi:10.2478/ johr-2013-0010

Ozcan, M. M. \& Al Juhaimi, F. Y. (2017). Effect of microwave roasting on yield and fatty acid composition of grape seed oil. Chemistry of Natural Compounds, 53(1), 132134. doi:10.1007/s10600-017-1926-2

Pavlousek, P. \& Kumsta, M. (2011). Profiling of primary metabolites in grapes of interspecific grapevine varieties: sugars and or- 
ganic acids. Czech Journal of Food Sciences, 29(4), 361-372.

Rogiers, S. Y., Greer, D. H., Hatfield, J. M., Orchard, B. A., \& Keller, M. (2006). Mineral sinks within ripening grape berries (Vitis vinifera L.) Vitis, 45(3), 115-123.

Rolle, L., Giacosa, S., Gerbi, V., Bertolino, M., \& Novello, V. (2013). Varietal comparison of the chemical, physical, and mechanical properties of five colored table grapes. International Journal of Food Properties, 16(3), 598-612. doi:10 . 1080 / 10942912 . 2011.558231

Santos, L. P., Morais, D. R., Souza, N. E., Cottica, S. M., Boroski, M., \& Visentainer, J. V. (2011). Phenolic compounds and fatty acids in different parts of Vitis labrusca and $V$. vinifera grapes. Food Research International, 44(5), 1414-1418. doi:10.1016/j . foodres.2011.02.022

Shiozaki, S. \& Murakami, K. (2016). Lipids in the seeds of wild grapes native to japan: Vitis coignetiae and Vitis ficifolia var. ganebu. Scientia Horticulturae, 201, 124129. doi:10.1016/j.scienta.2016.01.038

Slavin, J. L. \& Lloyd, B. (2012). Health benefits of fruits and vegetables. Advances in $\mathrm{Nu}$ trition, 3(4), 506-516. doi:10.3945/an.112. 002154

Sousa, E. C., Uchoa-Thomaz, A. M. A., Beserra Carioca, J. O., De Morais, S. M., De Lima, A., Martins, C. G., ... Rodrigues, L. L. (2014). Chemical composition and bioactive compounds of grape pomace (Vitis vinifera $\mathrm{L}$.), benitaka variety, grown in the semiarid region of Northeast Brazil. Food Science and Technology, 34(1), 135-142. doi:10.1590/S0101-20612014000100020

Topalovic, A. \& Mikulic-Petkovsek, M. (2010). Changes in sugars, organic acids and phenolics of grape berries of cultivar cardinal during ripening. Journal of Food Agriculture $\mathcal{E}$ Environment, 8(3-4, 1), 223-227.

Xia, E.-Q., Deng, G.-F., Guo, Y.-J., \& Li, H.-B. (2010). Biological activities of polyphenols from grapes. International Journal of Molecular Sciences, 11(2), 622-646. doi:10. 3390/ijms11020622

Xu, C., Yagiz, Y., Zhao, L., Simonne, A., Lu, J., \& Marshall, M. R. (2017). Fruit quality, nu- traceutical and antimicrobial properties of 58 muscadine grape varieties (Vitis rotundifolia michx.) grown in united states. Food Chemistry, 215, 149-156. doi:10.1016/j . foodchem.2016.07.163

Yamamoto, L. Y., de Assis, A. M., Roberto, S. R., Bovolenta, Y. R., Nixdorf, S. L., Garcia-Romero, E., ... HermosinGutierrez, I. (2015). Application of abscisic acid (S-ABA) to cv. Isabel grapes (Vitis vinifera $\mathrm{x}$ Vitis labrusca) for color improvement: Effects on color, phenolic composition and antioxidant capacity of their grape juice. Food Research International, $77(3), \quad 572-583$. doi:10.1016/j.foodres.2015.10.019

Zhou, K. \& Raffoul, J. (2012). Potential anticancer properties of grape antioxidants. Journal of Oncology, 1(8). doi:10.1155 / 2012/803294 